\title{
Video Article \\ Photogeneration of N-Heterocyclic Carbenes: Application in Photoinduced Ring-Opening Metathesis Polymerization
}

\author{
Julien Pinaud ${ }^{1}$, Emeline Placet ${ }^{1}$, Patrick Lacroix-Desmazes ${ }^{1}$, Thi Kim Hoang Trinh $^{2,3}$, Jean Pierre Malval ${ }^{2,3}$, Abraham Chemtob ${ }^{2,3}$, Loïc Pichavant ${ }^{4}$, \\ Valérie Héroguez ${ }^{4}$ \\ ${ }^{1}$ ICGM, Université de Montpellier, CNRS, ENSCM \\ ${ }^{2}$ Institut de Science des Matériaux de Mulhouse (IS2M UMR 7361 CNRS), Université de Haute-Alsace \\ ${ }^{3}$ Université de Strasbourg \\ ${ }^{4}$ Laboratoire de Chimie des Polymères Organiques (LCPO UMR 5629 ENSCBP), Université de Bordeaux
}

Correspondence to: Julien Pinaud at julien.pinaud@umontpellier.fr

URL: https://www.jove.com/video/58539

DOI: doi: $10.3791 / 58539$

Keywords: Chemistry, Issue 141, Polymer, ring-opening, metathesis, ROMP, carbene, NHC, photochemistry, miniemulsion, photolysis, photoreactor, photoreactivity

Date Published: 11/29/2018

Citation: Pinaud, J., Placet, E., Lacroix-Desmazes, P., Trinh, T.K., Malval, J.P., Chemtob, A., Pichavant, L., Héroguez, V. Photogeneration of NHeterocyclic Carbenes: Application in Photoinduced Ring-Opening Metathesis Polymerization. J. Vis. Exp. (141), e58539, doi:10.3791/58539 (2018).

\section{Abstract}

We report a method to generate the $\mathrm{N}$-heterocyclic carbene (NHC) 1,3-dimesitylimidazol-2-ylidene (IMes) under UV-irradiation at $365 \mathrm{~nm}$ to characterize IMes and determine the corresponding photochemical mechanism. Then, we describe a protocol to perform ring-opening metathesis polymerization (ROMP) in solution and in miniemulsion using this NHC-photogenerating system. To photogenerate IMes, a system comprising 2-isopropylthioxanthone (ITX) as the sensitizer and 1,3-dimesitylimidazolium tetraphenylborate $\left(\mathrm{IMesH}^{+} \mathrm{BPh}_{4}{ }^{-}\right)$as the protected form of $\mathrm{NHC}$ is employed. $\mathrm{IMesH}^{+} \mathrm{BPh}_{4}{ }^{-}$can be obtained in a single step by anion exchange between 1,3-dimesitylimidazolium chloride and sodium tetraphenylborate. A real-time steady-state photolysis setup is described, which hints that the photochemical reaction proceeds in two consecutive steps: 1) ITX triplet is photo-reduced by the borate anion and 2) subsequent proton transfer takes place from the imidazolium cation to produce the expected NHC IMes. Two separate characterization protocols are implemented. Firstly, $\mathrm{CS}_{2}$ is added to the reaction media to evidence the photogeneration of $\mathrm{NHC}$ through formation of the IMes- $\mathrm{CS}_{2}$ adduct. Secondly, the amount of $\mathrm{NHC}$ released in situ is quantified using acid-base titration. The use of this NHC photo-generating system for the ROMP of norbornene is also discussed. In solution, a photopolymerization experiment is conducted by mixing ITX, IMes $\mathrm{H}^{+} \mathrm{BPh}_{4}^{-}$, $\left[\mathrm{RuCl}_{2}(\mathrm{p} \text {-cymene })\right]_{2}$ and norbornene in $\mathrm{CH}_{2} \mathrm{Cl}_{2}$, then irradiating the solution in a UV reactor. In a dispersed medium, a monomer miniemulsion is first formed then irradiated inside an annular reactor to produce a stable poly(norbornene) latex.

\section{Video Link}

The video component of this article can be found at https://www.jove.com/video/58539/

\section{Introduction}

In chemistry, N-heterocyclic carbenes (NHCs) species fulfill the twofold role of ligand and organocatalyst ${ }^{1}$. In the former case, the introduction of NHCs has resulted in the design of metal transition catalysts with improved activity and stability ${ }^{2}$. In the latter case, NHCs have proved to be superior catalysts for manifold organic reactions $s^{3,4}$. Despite this versatility, handling bare NHCs is still a significant challenge ${ }^{5}$, and producing these highly reactive compounds so they are released in situ and "on demand" is a very attractive goal. Conseguently, several strategies have been developed to release $\mathrm{NHC}$ in the reaction media which mostly rely on the use of thermolabile progenitors ${ }^{6,7,8}$. Surprisingly, while this could unleash a novel generation of photoinitiated reactions useful for macromolecular synthesis or preparative organic chemistry ${ }^{6}$, generation using light as stimulus has been scarcely explored. Recently, a first photo-generating system able to produce NHC has been unveiled ${ }^{9}$. It consists of 2 components: 2-isopropylthioxanthone (ITX) as photosensitive species and 1,3-dimesitylimidazolium tetraphenylborate $\left(\mathrm{IMesH}^{+} \mathrm{BPh}_{4}{ }^{-}\right)$as the $\mathrm{NHC}$ protected form. Consequently, in the following paragraphs, we report a method to generate the NHC 1,3-dimesitylimidazol-2-ylidene (IMes) under UV-irradiation at $365 \mathrm{~nm}$, characterize it, and determine the photochemical mechanism. Then, we describe a protocol to perform ringopening metathesis polymerization (ROMP) in solution and in miniemulsion using this NHC photogenerating system.

In the first portion, we report a synthesis protocol to produce $\mathrm{IMesH}^{+} \mathrm{BPh}_{4}^{-}$. This protocol is based on anion metathesis between the corresponding imidazolium chloride $\left(\mathrm{IMesH}^{+} \mathrm{Cl}^{-}\right)$and sodium tetraphenylborate $\left(\mathrm{NaBPh}_{4}\right)$. Then, to demonstrate the in situ formation of $\mathrm{NHC}$, two protocols involving the irradiation at $365 \mathrm{~nm}$ of a $\mathrm{IMesH}^{+} \mathrm{BPh}_{4}^{-} / \mathrm{ITX}$ solution in a photoreactor are described. The first consists of monitoring the deprotonation of the imidazolium cation IMesH $\mathrm{H}^{+}$through ${ }^{1} \mathrm{H}$ NMR spectroscopy. Direct evidence for formation of the desired $\mathrm{NHC}$ (IMes) is provided in a second method, where the adduct IMes- $\mathrm{CS}_{2}$ is successfully isolated, purified, and characterized. 
The second section describes two protocols that shed light on the photochemical mechanism involving the NHC two-component photogenerating system IMesH ${ }^{+} \mathrm{BPh}_{4}{ }^{-} / \mathrm{ITX}$. Firstly, an original real-time steady state photolysis experiment reveals that electron transfer is induced by photoexcitation of ITX in the presence of tetraphenylborate. Electron donor properties of this borate anion ${ }^{10}$ drives a photoreduction of ${ }^{3}$ ITX ${ }^{*}$ triplet excited-state into ITX ${ }^{\circ-}$ radical anion through a so-called photo-sensitized reaction. The formation of NHC confirms that ITX ${ }^{\circ-}$ species may further abstract a proton from $\mathrm{IMesH}^{+}$to produce the desired $\mathrm{NHC}$. Based on acid/base titration using phenol red $\mathrm{pH}$ indicator as titrant, a second original protocol is implemented that allows the determination of the yield of released $\mathrm{NHC}$.

In the third section, we describe a protocol in which the above-mentioned photogenerated IMes can be exploited in photopolymerization. Of primary interest is ring-opening metathesis polymerization (ROMP), because this reaction is still at a preliminary stage of development with regard to photoinitiation ${ }^{11,12}$. Initially limited to ill-defined and highly sensitive tungsten complexes, photoinduced ROMP (photoROMP) has been extended to more stable complexes based on $\mathrm{W}, \mathrm{Ru}$, and Os transition metals. Despite the variety of precatalysts, almost all photoROMP processes rely on the direct excitation of a single photoactive precatalyst ${ }^{13}$. By contrast, we use radiation to create the $\mathrm{NHC}$ imidazolidene ligand (IMes), which can react subsequently with a non-photoactive Ru precatalyst $\left[\mathrm{RuCl}_{2}(p \text {-cymene })\right]_{2}$ dimer ${ }^{9}$. In this method, the photogeneration of $\mathrm{NHC}$ ligand drives the in situ formation of a highly active ruthenium-arene $\mathrm{NHC}$ complex known as $\mathrm{RuCl}_{2}\left(p\right.$-cymene)(IMes) (Noels' catalyst) ${ }^{14,15}$ Using this indirect methodology, two distinct photoROMP experiments of norbornene (Nb) are performed: 1) in solution (dichloromethane) and 2) in aqueous dispersed system from a monomer miniemulsion ${ }^{16}$.

\section{Protocol}

\section{NHC Photogenerating System: Synthesis and Reactivity}

1. Synthesis of 1,3-dimesitylimidazolium tetraphenylborate $\left(\mathrm{IMesH}^{+} \mathrm{BPh}_{4}{ }^{-}\right)$

1. Preparation of the solution of 1,3-dimesitylimidazolium chloride $\left(\mathrm{IMesH}^{+} \mathrm{Cl}^{-}\right)$in ethanol.

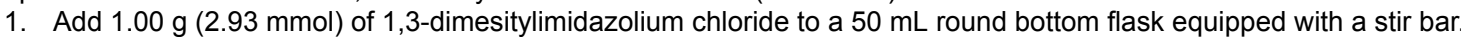

2. Dissolve the 1,3-dimesitylimidazolium chloride in $30 \mathrm{~mL}$ of ethanol.

2. Preparation of the solution of sodium tetraphenylborate $\left(\mathrm{NaBPh}_{4}\right)$ in ethanol.

1. Add $1.35 \mathrm{~g}(3.92 \mathrm{mmol})$ of sodium tetraphenylborate to a $50 \mathrm{~mL}$ round bottom flask equipped with a stir bar.

2. Dissolve the sodium tetraphenylborate in $30 \mathrm{~mL}$ of ethanol.

3. Generation of 1,3-dimesitylimidazolium tetraphenylborate $\left(\mathrm{IMesH}^{+} \mathrm{BPh}_{4}{ }^{-}\right)$

1. Add (dropwise) the solution of sodium tetraphenylborate into the solution of 1,3-dimesitylimidazolium chloride under stirring.

2. Stir the reaction mixture for $10 \mathrm{~min}$ at room temperature.

3. Remove the stir bar and filter the white precipitate using a vacuum and fritted glass filter of pore size 3 .

4. Wash the precipitate with $30 \mathrm{~mL}$ of ethanol and filter it (fritted glass filter with pore size 3). Wash the precipitate with $30 \mathrm{~mL}$ of deionized water and filter it (fritted glass filter with pore size 3 ).

5. Dry the white precipitate at $60{ }^{\circ} \mathrm{C}$ for $15 \mathrm{~h}$. Analyze the product by ${ }^{1} \mathrm{H}$ and ${ }^{13} \mathrm{C}$ NMR in DMSO- $\mathrm{d}_{6}$ according to previously reported procedures ${ }^{9}$.

2. Photogeneration of NHC 1,3-dimesitylimidazol-2-ylidene, also known as IMes, by UV irradiation of the dimesitylimidazolium tetraphenylborate in the presence of isopropylthioxanthone (ITX)

1. Add $39 \mathrm{mg}(0.062 \mathrm{mmol}, 2$ equiv. $)$ of 1,3-dimesitylimidazolium tetraphenylborate, $7.8 \mathrm{mg}(0.031 \mathrm{mmol}, 1 \mathrm{equiv}$. $)$ of ITX, and $0.5 \mathrm{~mL}$ of deuterated THF (previously stored over $3 \AA$ molecular sieves) in an NMR tube.

2. Place the NMR tube inside the photochemical reactor equipped with a circular array of 16 fluorescent tubes emitting a monochromatic radiation at $365 \mathrm{~nm}$ and irradiate for $10 \mathrm{~min}$.

3. Monitoring of deprotonation of $\mathrm{IMesH}^{+} \mathrm{BPh}_{4}{ }^{-}$by ${ }^{1} \mathrm{H}$ NMR spectroscopy

1. Analyze the deprotonation of $\mathrm{IMesH}^{+}$into IMes by ${ }^{1} \mathrm{H}$ NMR.

NOTE: ${ }^{1} \mathrm{H}$ NMR spectra were recorded at $25^{\circ} \mathrm{C}$ on a NMR spectrometer operating at $400 \mathrm{MHz}$. TMS was used as internal standards for calibrating the chemical shifts in ${ }^{1} \mathrm{H}$ NMR.

1. Calibrate the integration parameters so that in the ${ }^{1} \mathrm{H}$ NMR spectra the $\mathrm{CH}_{3}$ singlet of 1,3-dimesitylimidazolium tetraphenylborate $(\delta=2.0 \mathrm{ppm})$ corresponds to six.

2. Determine the integration value of the $\mathrm{N}-\mathrm{CH}-\mathrm{N}$ signal area $(\delta=8.4-9.4 \mathrm{ppm})$ in order to evaluate the degree of IMesH $\mathrm{H}^{+}$ deprotonation. The integration value should vary from 1 (when no deprotonation occurred, before irradiation) to 0 (when complete deprotonation of $\mathrm{IMesH}^{+}$has been performed).

4. Formation, isolation, and characterization of the 1,3-dimesitylimidazoliumdithio-carboxylate adduct (IMes-CS 2 )

1. Add $0.02 \mathrm{~mL}$ of carbon disulfide in the as-irradiated NMR tube. The reaction media changes in color from orange/brown to dark red, indicating the formation of the IMes- $\mathrm{CS}_{2}$ adduct.

2. Let it react for $12 \mathrm{~h}$. A red precipitate forms assigned to the IMes-CS $\mathrm{C}_{2}$ adduct.

3. Filter the red precipitate (fritted glass filter with pore size 3 ) and dry it under air at room temperature for $12 \mathrm{~h}$.

4. Solubilize the red solid in $0.5 \mathrm{~mL}$ of deuterated DMSO. Confirm the chemical structure by ${ }^{1} \mathrm{H}$ and ${ }^{13} \mathrm{C}$ NMR spectroscopy. CAUTION: Carbon disulfide is highly toxic and should be handled with care under a fume hood. 


\section{Photochemical Mechanism}

1. Real-time photobleaching of $\mathrm{IMesH}^{+} \mathrm{BPh}_{4}{ }^{-} / \mathrm{ITX}$

1. Prepare a stock solution of ITX by adding $0.76 \mathrm{mg}\left(3 \times 10^{-3} \mathrm{mmol}\right)$ of ITX to $15 \mathrm{~mL}$ of dry acetonitrile (previously stored over $3 \AA$ molecular sieves).

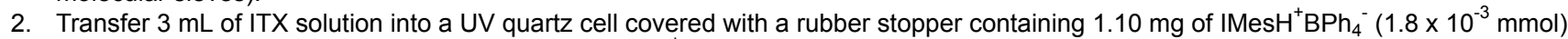
and a stirring micromagnet. The molar ratio ITX:IMesH ${ }^{+} \mathrm{BPh}_{4}{ }^{-}$is $1: 3$.

3. Degas the solution by bubbling nitrogen for $10 \mathrm{~min}$, then irradiate the solution at $365 \mathrm{~nm}$ with a medium-pressure $\mathrm{Hg}$-Xe lamp under continuous stirring (63 $\mathrm{mW} \mathrm{cm} \mathrm{cm}^{-2}$, power of $75 \mathrm{~mW}$ ).

4. Monitor the change of UV-absorbance at $365 \mathrm{~nm}$ during irradiation by using a spectrometer after passing a transmitted actinide beam

5. Apply the same procedure (steps 2.1.1-2.1.4) for other experiments but replace $\mathrm{IMesH}^{+} \mathrm{BPh}_{4}{ }^{-}$with other quenchers: IMesH ${ }^{+} \mathrm{Cl}^{-}(0.61$ $\left.\mathrm{mg}, 1.8 \times 10^{-3} \mathrm{mmol}\right)$ or $\mathrm{NaBPh}_{4}\left(0.62 \mathrm{mg}, 1.8 \times 10^{-3} \mathrm{mmol}\right)$.

2. Quantification of photogenerated NHC by spectrophotometric titration

1. Add $1.85 \mathrm{mg}$ of dimesitylimidazolium tetraphenylborate $\left(3 \times 10^{-4} \mathrm{mmol}, 3\right.$ equiv. $)$ and $0.25 \mathrm{mg}$ of ITX (10 $0^{-4} \mathrm{mmol}, 1$ equiv. $)$ to $10 \mathrm{~mL}$ of dry acetonitrile.

2. Transfer $2 \mathrm{~mL}$ of this freshly prepared solution into a conventional spectroscopic quartz cell capped with a rubber septum.

3. Purge the colorless mixture with nitrogen before exposing the cuvette to a $365 \mathrm{~nm}$ LED spotlight (power of $65 \mathrm{~mW}$ ) for $1 \mathrm{~min}$.

4. After each irradiation time, add gradually $0.1 \mathrm{~mL}$ portions of phenol red (PR) solution $\left(2 \times 10^{-4} \mathrm{M}\right.$ in dry acetonitrile) into the cuvette. This latter titrating solution was prepared in advance.

5. Record a UV-vis spectrum after each $0.1 \mathrm{~mL}$ addition of $\mathrm{PR}$ solution until reaching $1 \mathrm{~mL}$.

NOTE: The indicator solution is initially transparent and contains the bis-protonated form $\mathrm{H}_{2} \mathrm{PR}$. After its addition, acid/base reaction with $\mathrm{NHC}$ causes the formation of the pink bivalent anion $\mathrm{PR}^{2-}$ with a maximum absorption at $580 \mathrm{~nm}$. Plotting the absorbance at 580 $\mathrm{nm}$ as a function of the titrant volume gives two intersecting straight lines, indicative of the titration endpoint.

6. Repeat the same procedure (steps 2.2.1-2.2.5) with the same ITX/IMes $\mathrm{H}^{+} \mathrm{BPh}_{4}{ }^{-}$solution irradiated for longer times: 2 min, 5 min, and 10 min. For each time, a new IMesH ${ }^{+} \mathrm{PH}_{4}^{-} / \mathrm{ITX}$ sample must be prepared.

NOTE: At the equivalence point in the acid-base titration:

$[\mathrm{IMes}] \times \mathrm{V}=2[\mathrm{PR}] \times \mathrm{V}_{\mathrm{eq}}$

Where [IMes] is the concentration of photogenerated IMes released in the UV cuvette, $V$ is the initial volume of $I \mathrm{IMesH}^{+} \mathrm{BPh}_{4}{ }^{-}$

ITX solution, [PR] is the concentration of PR, and $V_{\text {eq }}$ is the total volume of PR added into the UV cuvette at the titration end-point. Therefore, the yield of IMes released upon irradiation of $\mathrm{IMesH}^{+} \mathrm{BPh}_{4}{ }^{-} / \mathrm{ITX}$ solution is obtained from equation (2):

Yield $(\%)=\frac{2 *[\mathrm{PR}] \times \mathrm{V}_{\mathrm{eq}}}{\left[\mathrm{IMesH}^{+} \mathrm{BPh}_{4}^{-}\right] \times \mathrm{V}} \times 100$

Where $\left[\mathrm{IMesH}^{+} \mathrm{BPh}_{4}^{-}\right]$is the initial concentration of $\mathrm{IMesH}^{+} \mathrm{BPh}_{4}^{-}$.

The validity of the method is checked by titrating a free IMes solution $\left(1 \times 10^{-4} \mathrm{M}\right.$ in acetonitrile $)$ using a similar acetonitrile PR solution as a titrant $\left(2 \times 10^{-4} \mathrm{M}\right)$.

\section{Photoinduced Ring-Opening Metathesis Polymerization}

1. PhotoROMP of $\mathrm{Nb}$ in solution

1. Add $1 \mathrm{~g} \mathrm{(11} \mathrm{mmol,} 540$ equiv.) of $\mathrm{Nb}, 120 \mathrm{mg} \mathrm{(0.196} \mathrm{mmol,} 10$ equiv.) of 1,3-dimesitylimidazolium tetraphenylborate, $12 \mathrm{mg}(19.6 \mathrm{mmol}$, 1 equiv.) of dichloro(para-cymene)ruthenium dimer, and $25 \mathrm{mg}(0.098 \mathrm{mmol}, 5$ equiv.) of ITX in a $20 \mathrm{~mL}$ test tube equipped with a stir bar.

2. Dissolve the solids in $10 \mathrm{~mL}$ of dichloromethane and cap the tube with a rubber septum.

3. Purge the mixture by bubbling nitrogen gas through a syringe needle for $15 \mathrm{~min}$.

4. Place the tube inside the photochemical reactor equipped with a circular array of 16 fluorescent lamps (emitting at $365 \mathrm{~nm}$ ) and irradiate for $10 \mathrm{~min}$. The solution becomes viscous, indicating that high-molecular weight poly Nb is formed.

5. Precipitate the polymer by pouring the solution into $300 \mathrm{~mL}$ of methanol.

6. Filter the polymer (fritted glass filter with pore size 3 ) and dry it at $60^{\circ} \mathrm{C}$ for $8 \mathrm{~h}$.

7. Analyze the polymer by ${ }^{1} \mathrm{H}$ NMR according to reported procedures ${ }^{9}$ by dissolving about $10 \mathrm{mg}$ of polymer in $0.5 \mathrm{~mL}^{\circ} \mathrm{CD}_{2} \mathrm{Cl}_{2}$

8. Analyze the polymer by size exclusion chromatography according to reported procedures ${ }^{9}$, using THF as eluent and dissolving 10 mg of polymer in $1 \mathrm{~mL}$ of THF.

2. PhotoROMP of $\mathrm{Nb}$ in miniemulsion

1. Preparation of $\mathrm{Nb}$ miniemulsion.

1. Dissolve $15.0 \mathrm{~g}$ of neutral surfactant polyoxyethylene (100) stearyl ether in $150 \mathrm{~mL}$ of milliQ water

2. Introduce the aqueous phase in the annular LED photoreactor closed with rubber septum and place the reactor under the airtight sonication probe.

3. Degas the solution by bubbling nitrogen during $1 \mathrm{~h}$.

4. Mix $4.94 \mathrm{~g}$ of Nb $\left(5.2 \times 10^{-2} \mathrm{~mol} ; 510\right.$ equiv.; $\left.25 \mathrm{w} \%\right), 2.85 \mathrm{~mL}$ of hexadecane $(10 \mathrm{w} \%)$, and $6 \mathrm{~mL}$ of dichloroethane (32.5 w\%) in a $50 \mathrm{~mL}$ round bottom flask closed with a rotaflo. Degas the solution with a freeze-pump-thaw cycle.

5. Add $6 \mathrm{~mL}$ of dichloroethane $(32.5 \mathrm{w} \%)$ in a second $50 \mathrm{~mL}$ round-bottom flask closed with a rotaflo. Degas the solution by freezepump-thaw. Add $162 \mathrm{mg}$ of 1,3-dimesitylimidazolium tetraphenylborate (2.6 x 10 $0^{-4} \mathrm{~mol}, 5$ equiv.), $33 \mathrm{mg}$ of ITX (1.3 $10^{-4} \mathrm{~mol}, 2.5$ equiv.), and $30 \mathrm{mg}$ of dichloro(p-cymene)ruthenium(II) dimer $\left(4.9 \times 10^{-5} \mathrm{~mol}, 1\right.$ equiv.) under inert atmosphere (glovebox) to the flask. 
6. Mix the two organic solutions containing the monomer and the catalytic mixture under a nitrogen flux, and introduce $15 \mathrm{~g}$ of the final organic solution inside the photoreactor, containing the aqueous phase under stirring.

7. Stir the two phases during $1 \mathrm{~h}$ to form a rough macroemulsion. Sonicate during $10 \mathrm{~min}$ (power $50 \%$; pulse on-time: $5 \mathrm{~s}$, off-time: $5 \mathrm{~s})$ to form the miniemulsion.

2. Photopolymerization of NB miniemulsion.

1. Replace the airtight sonication probe by the LED lamp equipped with a water cooling system and protected by a cladding tube under a nitrogen flux.

2. Place the closed reactor inside the photocabinet to prevent exposure to UV radiation.

3. Irradiate the monomer miniemulsion for $100 \mathrm{~min}$ to obtain polymer latex. During irradiation, particle size and monomer conversion can be determined as explained below.

3. Determination of particle size, conversion and molecular weight.

1. Collect $4 \mathrm{~mL}$ of miniemulsion sample during irradiation process.

2. Add $20 \mu \mathrm{L}$ of miniemulsion in a glass cuvette containing $5 \mathrm{~mL}$ water to prepare a $250 \mathrm{x}$ diluted sample for particle size analysis by dynamic light scattering (DLS).

3. Dissolve $100 \mu \mathrm{L}$ of miniemulsion in $500 \mu \mathrm{L}$ of $\mathrm{THF}$ to measure the $\mathrm{Nb}$ conversion by gas chromatography (GC), with hexadecane as internal standard ( $\mathrm{GC}$ retention times: $\mathrm{t}_{\mathrm{Nb}}^{\mathrm{GC}}=1.77 \mathrm{~min} ; \mathrm{t}_{\text {dodecane }}^{\mathrm{GC}}=13.25 \mathrm{~min}$ ).

4. Precipitate the rest of the sample in $20 \mathrm{~mL}$ of acetone. Filter the polymer. Dry the polymer under a vacuum and measure the molecular weight by size exclusion chromatography (SEC) [SEC in tetrahydrofuran (THF) $\left(1 \mathrm{~mL} \mathrm{~min}^{-1}\right)$ with trichlorobenzene as the flow marker, using both refractometric and UV detectors]

CAUTION (Part 1-3): Possibly hazardous sources of light emitting in the UV and visible range are used in the described experiments. These lamps can present a reasonably foreseeable risk of harming the eyes and skin of lab members. Consequently, all measures possible should be put in place by the experimenter to reduce the risks to as low as is reasonably practicable. A list of common measures includes the isolation of the light source inside a protective casing (photocabinet, for example), training of all workers, placing the hazardous sources of light in well-designated laboratories or fume hoods with restricted access, providing suitable safety gears (safety goggles blocking UVA irradiation are sufficient for all described protocols), and displaying appropriate warning and safety signs.

\section{Representative Results}

Step 1.1 describes the efficient anion metathesis between 1,3-dimesitylimidazolium chloride $\left(\mathrm{IMesH}^{+} \mathrm{Cl}^{-}\right)$and sodium tetraphenylborate $(\mathrm{NaBPh})$ to yield 1,3-dimesitylimidazolium tetraphenylborate $\left(\mathrm{IMesH}^{+} \mathrm{BPh}_{4}^{-}\right)$. The desired photolatent $\mathrm{NHC}$ is obtained in excellent yield (98\%). Figure 1 shows ${ }^{1} \mathrm{H}$ and ${ }^{13} \mathrm{C}$ NMR spectra, both testifying that a pure product exhibiting the correct structure is obtained.

Step 1.2 describes how to generate the $\mathrm{N}-\mathrm{HC}$ IMes by irradiating the mixture $\mathrm{IMesH}^{+} \mathrm{BPh}_{4}{ }^{-} / \mathrm{ITX}(2 / 1$ equiv. $)$ in $\mathrm{THF}^{-\mathrm{d}_{8}}$ solution.

Step 1.3 shows that it is possible to assess the conversion of IMes $\mathrm{H}^{+}$in IMes by monitoring the deprotonation of IMesH $\mathrm{H}^{+} \mathrm{BPh}_{4}{ }^{-}$through ${ }^{1} \mathrm{H} \mathrm{NMR}^{-}$ spectroscopy. Figure 2 shows that proton $\mathrm{H}_{\mathrm{a}}(8.63 \mathrm{ppm}$, Figure 2a) on carbon 2 adjacent to the two nitrogen atoms disappears partially after 10 min irradiation ( $53 \%$, Figure $\mathbf{2 b}$ ). The reaction was performed by irradiating the mixture $\mathrm{IMesH}^{+} \mathrm{BPh}_{4}{ }^{-} / \mathrm{ITX}(2 / 1$ equiv.) in THF-d 8 solution.

Step 1.4 shows that it is possible to isolate the formed $\mathrm{NHC}$ by reacting the as-irradiated medium (see protocol 1.2) with $\mathrm{CS}_{2}$. The red precipitate formed in THF- $d_{8}$ is collected, dried, and dissolved in DMSO- $d_{6}$. As can be seen in the ${ }^{13} \mathrm{C}$ NMR spectrum (Figure 2c), all the characteristic resonances are consistent with IMes- $\mathrm{CS}_{2}$ adduct. This result indirectly confirms the in situ generation of the targeted IMes NHC.

Step 2.1: Thioxanthone derivatives make up a well-established class of photoinitiators generally employed in combination with a second component referred to as "co-initiators". Their absorption spectra appear with a maximum in the range of $340-420 \mathrm{~nm}$. The nature of the coinitiator determines the mechanism of initiation. Three general initiation mechanisms have been described: 1) triplet-triplet energy transfer (in

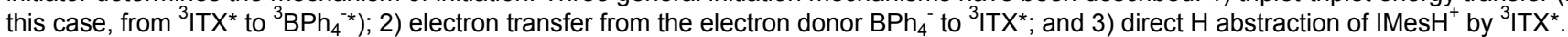
Mechanism 1 can be discarded since the triplet energy order $\mathrm{E}_{\mathrm{T}}\left(\mathrm{BPh}_{4}{ }^{-}\right)>\mathrm{E}_{\mathrm{T}}(\mathrm{ITX})$ is established by conventional computational procedure.

Step 2.1 provides evidence as to whether mechanism 2 or 3 is operating. Figure 3 shows the evolution of absorbance values of characteristic ITX absorption band at $365 \mathrm{~nm}$ during irradiation for three different bicomponent mixtures: IMesH $\mathrm{HPPh}_{4}{ }^{-} / \mathrm{ITX}, \mathrm{IMesH}^{+} \mathrm{Cl}^{-} / \mathrm{ITX}$, and $\mathrm{NaBPh} / / \mathrm{ITX}$ The absence of decay for IMes $\mathrm{H}^{+} \mathrm{Cl}^{-}$supports the incapacity for electronically excited ITX to abstract a hydrogen from the imidazolium cation (mechanism 3). In contrast, photobleaching of ITX is visible in the two systems containing the $\mathrm{BPh}_{4}{ }^{-}$anions; although, the decay rates are different in these two cases. This result emphasizes the critical role played by the tetraphenylborate anion. Consequently, the photoreduction of ITX by tetraphenylborate (mechanism 2) is proven to be the primary step in the formation of the NHC. Figure 4 displays a hypothetical and complete mechanism in which the ITX ${ }^{\bullet-}$ radical anion may abstract a proton from IMesH ${ }^{+}$to release the free $\mathrm{NHC}$ IMes.

Step 2.2 shows evidence in favor of this mechanism. This method reveals the progressive release of NHC during irradiation. It is a method to determine the amount of released $\mathrm{NHC}$ based on acid/base titration using phenol red (PR) pH indicator as titrant. A maximum yield of $50 \%$ is achieved after 5 min of irradiation (Figure 5), and a control experiment with free IMes enables validation of the method. 
Step 3.1 describes photoROMP of NB (540 equiv.) in dichloromethane using a photolatent mixture composed of IMesH ${ }^{+} \mathrm{BPh}_{4}{ }^{-} / \mathrm{ITX}(10 / 5$ equiv.) (to produce $\mathrm{NHC}$ IMes) and the well-known inactive $\left[\mathrm{RuCl}_{2}(p \text {-cymene) }]_{2}\right.$ dimer (1 equiv.). It is recognized that the simple reaction of Ru precatalyst with the imidazolidene ligand IMesis a means to generate in situ the highly active ruthenium-arene complex RuCl $2(p$-cymene $)(\mathrm{NHC})$, also known as Noels' catalyst. Irradiation is performed in a conventional photochemical reactor $\left(\lambda_{\max }=365 \mathrm{~nm}\right)$ at room temperature. Complete conversion is achieved after only $10 \mathrm{~min}$ of irradiation as measured by ${ }^{1} \mathrm{H}$ NMR spectroscopy (Figure 6), suggesting successful formation of the highly active ruthenium-arene complex bearing an $\mathrm{NHC}$ ligand. In addition, poly $\mathrm{Nb}$ [with a number-average molecular weight of $288 \mathrm{kDa}$ and relatively narrow dispersity values $(\Theta=1.5)]$ is obtained as determined by size exclusion chromatography.

Step 3.2 describes a miniemulsion photoROMP procedure. High conversions (70-80\%) are achieved (Figure 7). As can be seen in Figure 8, the initial droplet size measured by DLS is $92 \mathrm{~nm}$. The final particles exhibit a size of $102 \mathrm{~nm}(0.140)$ close to the initial droplet size. TEM observations show perfectly spherical particles with sizes in agreement with DLS data.

a)

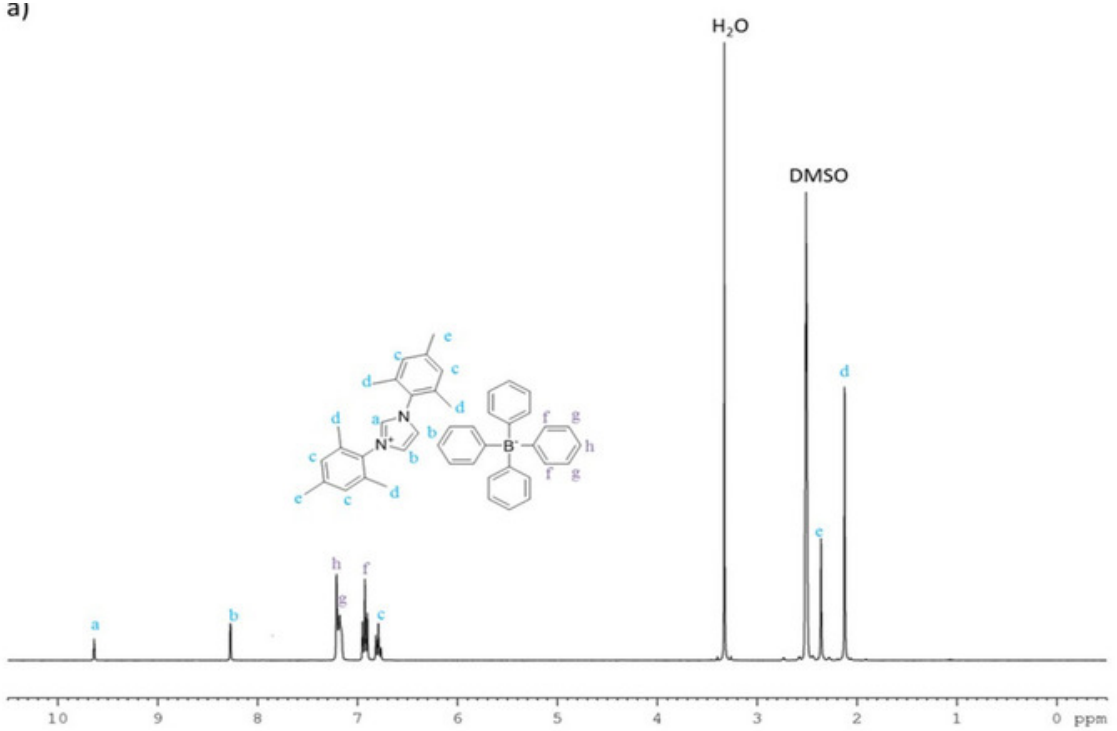

b)
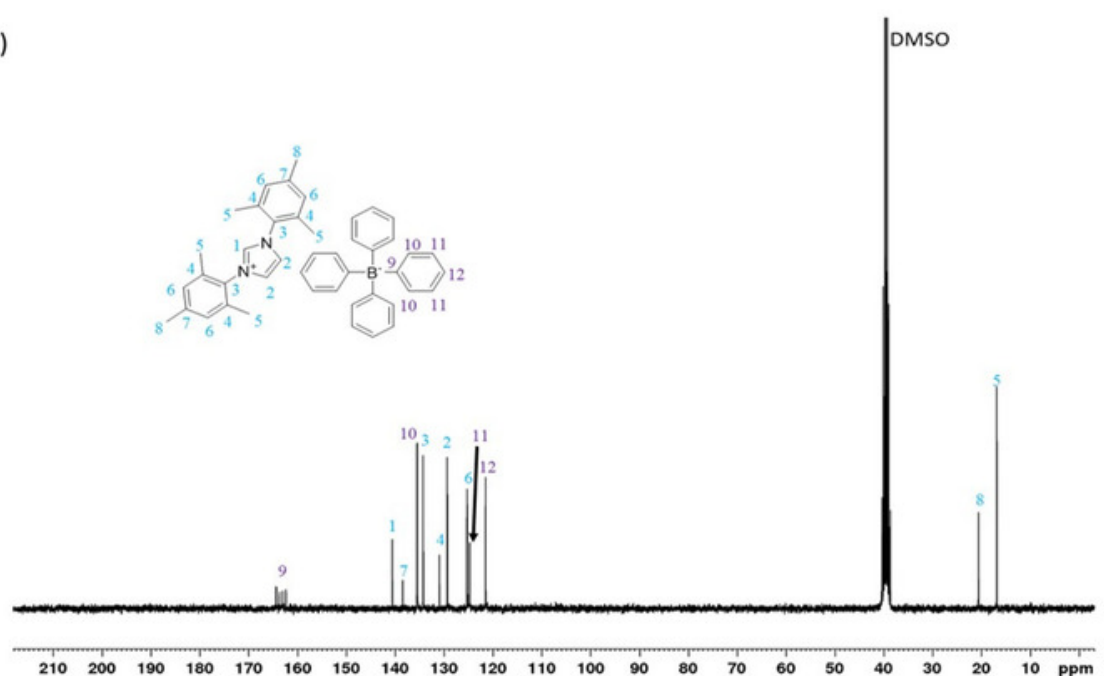

Figure 1: NMR characterization of IMesH ${ }^{+} \mathrm{BPh}_{4}{ }^{-}$. (a) ${ }^{1} \mathrm{H}$ NMR spectrum in DMSO- $d_{6}(400 \mathrm{MHz})$ of 1,3-dimesitylimidazolium tetraphenylborate $\left(\mathrm{IMesH}^{+} \mathrm{BPh}_{4}^{-}\right), \delta_{\mathrm{ppm}}: 2.13(\mathrm{~s}, 12 \mathrm{H}), 2.36(\mathrm{~s} .6 \mathrm{H}), 6.69(\mathrm{t}, 4 \mathrm{H}), 7.17(\mathrm{~m}, 2 \mathrm{H}), 8.27(\mathrm{~s}, 2 \mathrm{H}), 9.64(\mathrm{~s}, 1 \mathrm{H}$,$) ; (b) { }^{13} \mathrm{C}$ NMR spectrum of the same compound in DMSO- $d_{6}(100 \mathrm{MHz}), \delta_{\mathrm{ppm}}: 16.58,20.23,121.35,124.49,125.02,129.24,130.29,134.00,135.35,138.19,140.06,162.58 . \mathrm{T}_{\mathrm{m}}=$ $212{ }^{\circ} \mathrm{C}$ (DSC). This figure has been modified from a previous publication ${ }^{9}$. Please click here to view a larger version of this figure. 
a)

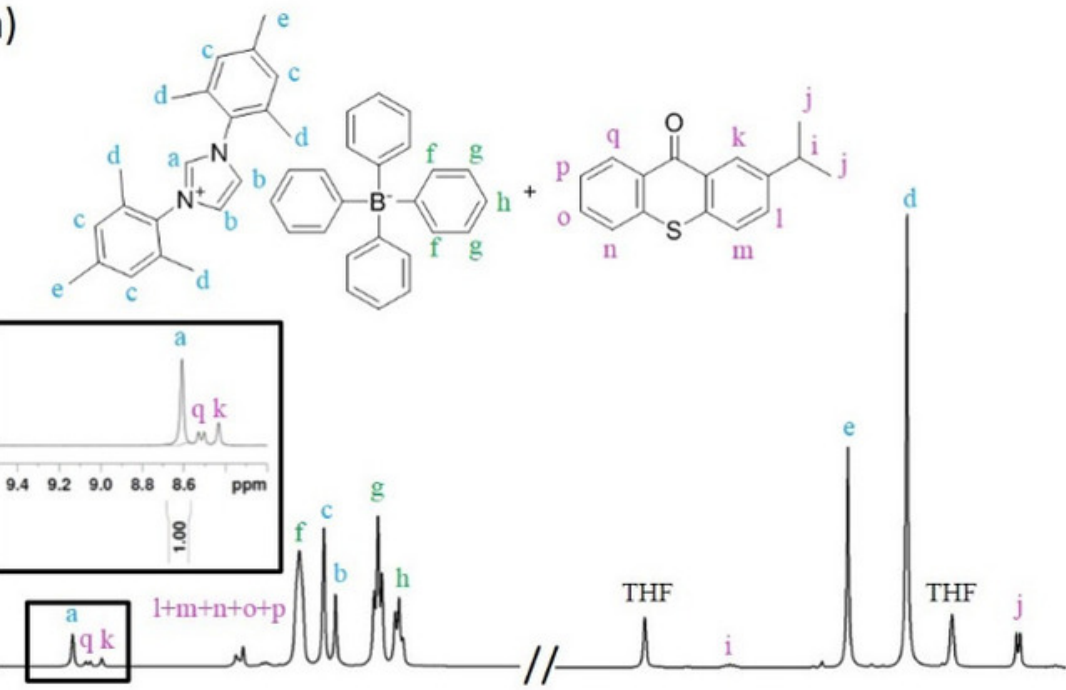

b)

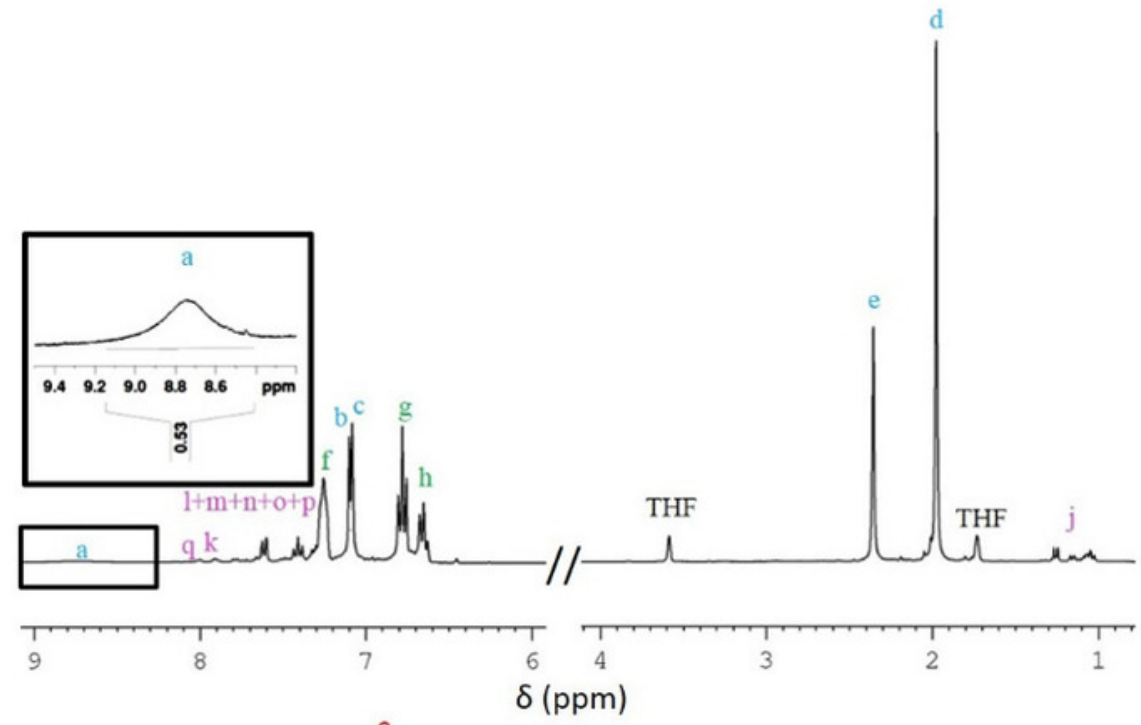

c)

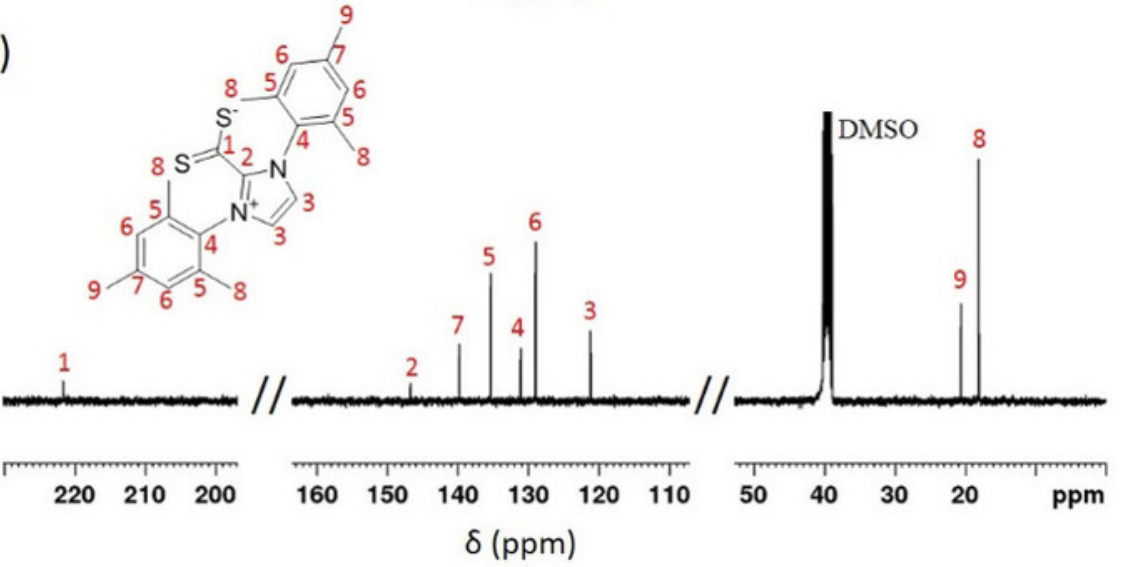

Figure 2: NMR monitoring of IMesH ${ }^{+} \mathrm{BPh}_{4}{ }^{-}$deprotonation and subsequent synthesis of IMes- $\mathrm{CS}_{2} .{ }^{1} \mathrm{H} \mathrm{NMR}^{-}$spectra of IMesH ${ }^{+} \mathrm{BPh}_{4}{ }^{-} / \mathrm{ITX}$ (2/1 equiv.)mixturein THF- $d_{8}$ (a) before UV exposure and (b) after 10 min irradiation at $365 \mathrm{~nm}\left(0.12 \mathrm{~mW} \mathrm{~cm}^{-2}\right)$ in a photochemical reactor; shown are $(c){ }^{13} \mathrm{C}$ NMR spectra in DMSO- $d_{6}$ of the precipitate recovered after addition of $\mathrm{CS}_{2}$. This figure has been modified from a previous publication ${ }^{9}$. Please click here to view a larger version of this figure. 


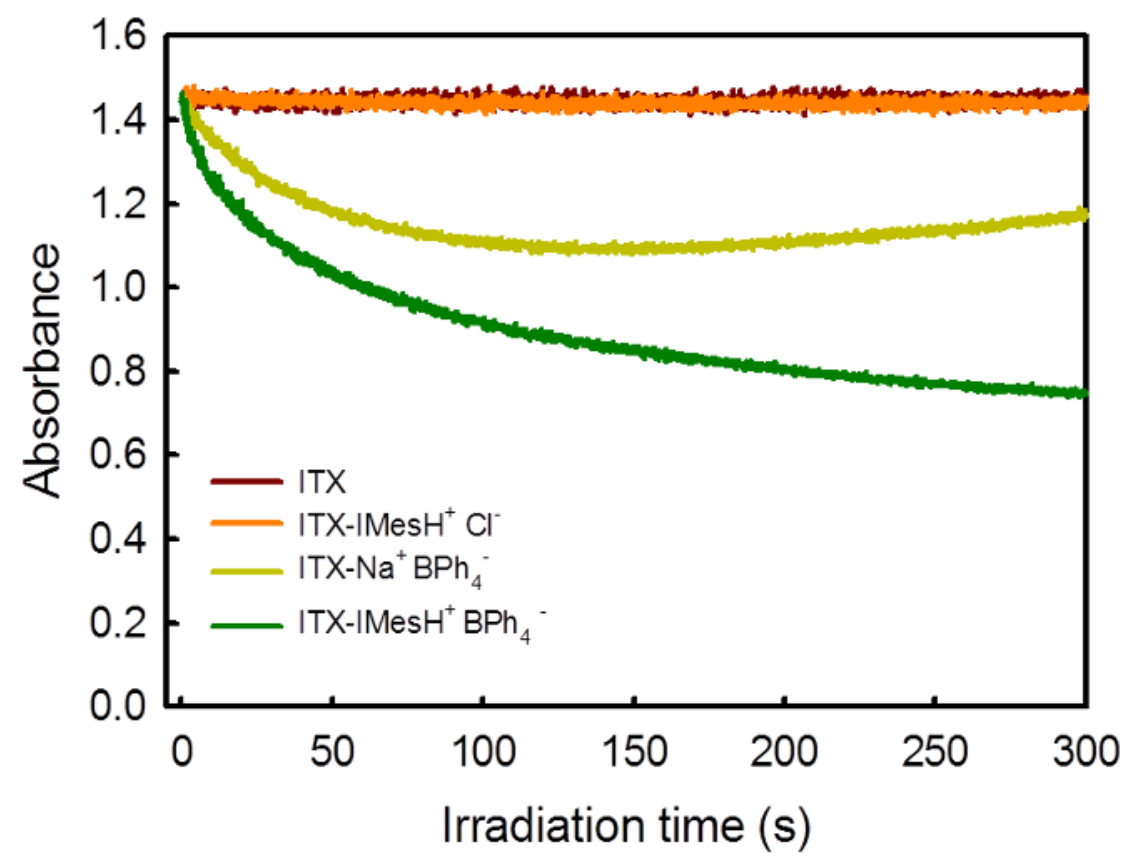

Figure 3: Evidence for photolysis mechanism. Real-time photobleaching experiments in acetonitrile (irradiation: $365 \mathrm{~nm}, 63 \mathrm{~mW} \mathrm{~cm}^{-2}$ ): ITX,

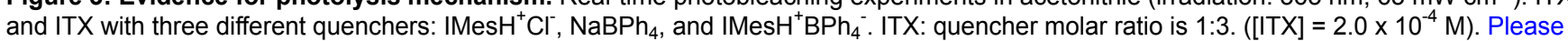
click here to view a larger version of this figure.

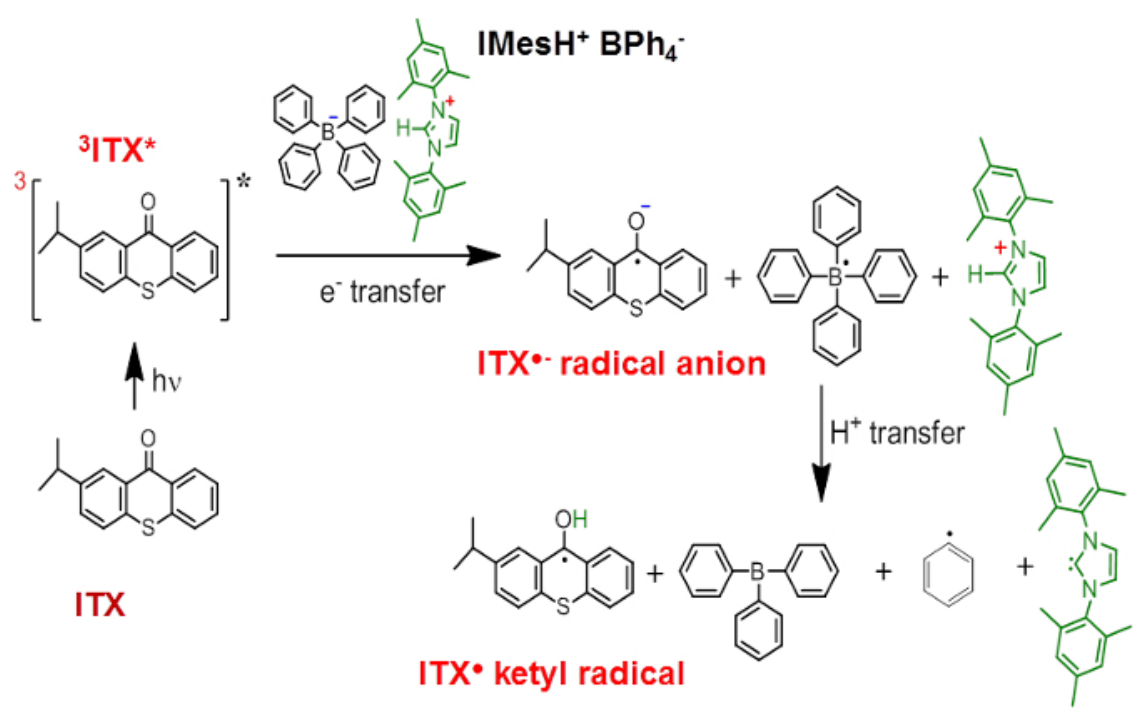

Free IMes

Figure 4: Photomechanism pathway to IMes. Photolysis mechanism of the $\mathrm{IMesH}^{+} \mathrm{BPh}_{4}{ }^{-} / \mathrm{ITX}$ tandem system. Please click here to view a larger version of this figure. 

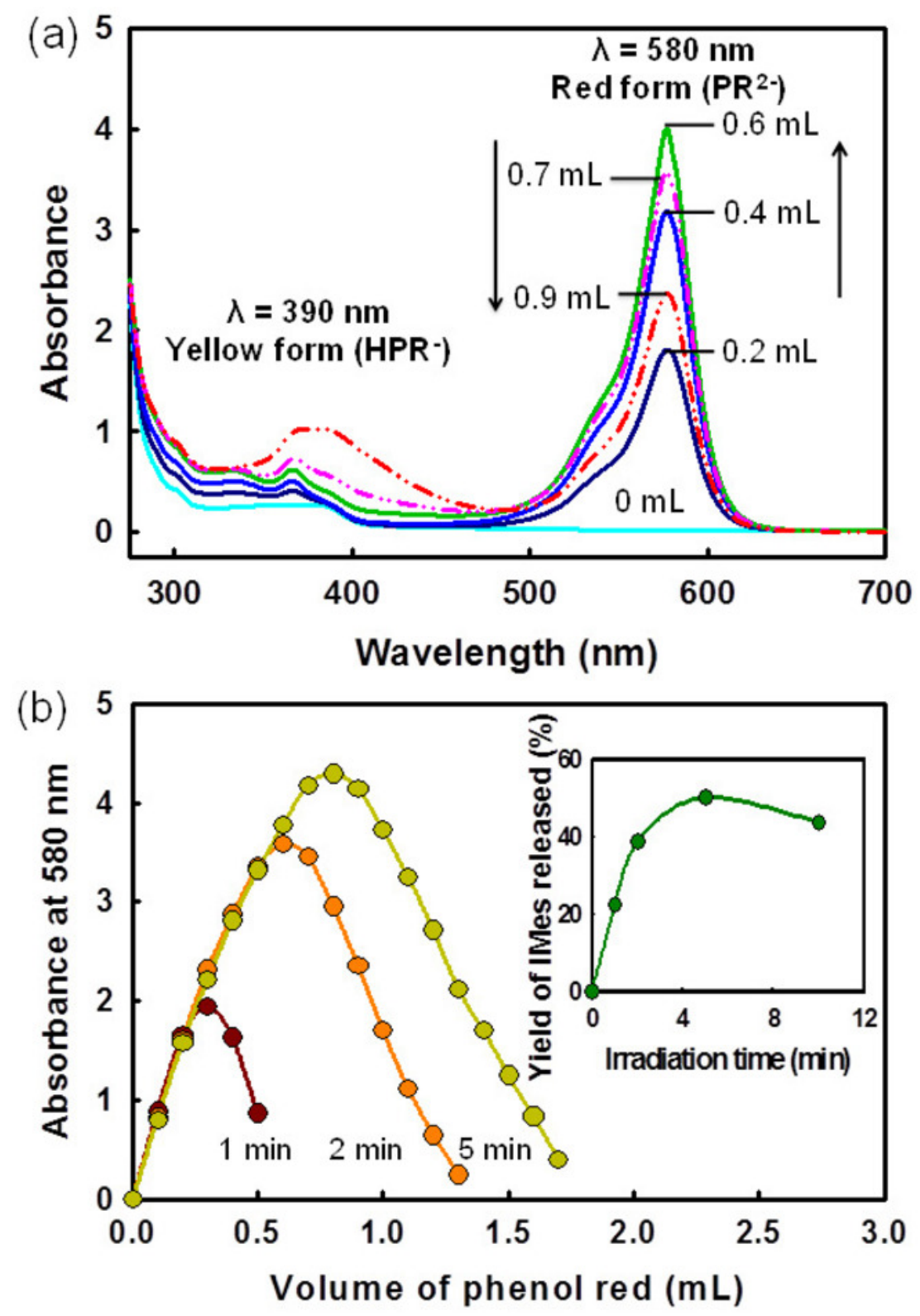

Figure 5: Quantification of IMes amount released. (a) Change of UV-Vis spectra of an acetonitrile solution of IMesH $\mathrm{BPh}_{4}^{-}\left(3.0 \times 10^{-4}\right.$ M) and ITX $\left(1 \times 10^{-4} \mathrm{M}\right)$ irradiated for $2 \mathrm{~min}\left(\mathrm{LED}, 365 \mathrm{~nm}, 65 \mathrm{~mW} \mathrm{~cm}^{-2}\right)$ upon gradual addition of PR $\left(2 \times 10^{-4} \mathrm{M}\right)$; (b) titration plot showing the absorbance at $580 \mathrm{~nm}$ for the same solution irradiated at 1, 2, or $5 \mathrm{~min}$ as a function of PR (titrant) volume. The insert gives the yield of photogenerated NHCs deduced from the spectrophotometric titration curve. This figure has been modified from a previous publication ${ }^{9}$. Please click here to view a larger version of this figure. 
Journal of Visualized Experiments

www.jove.com

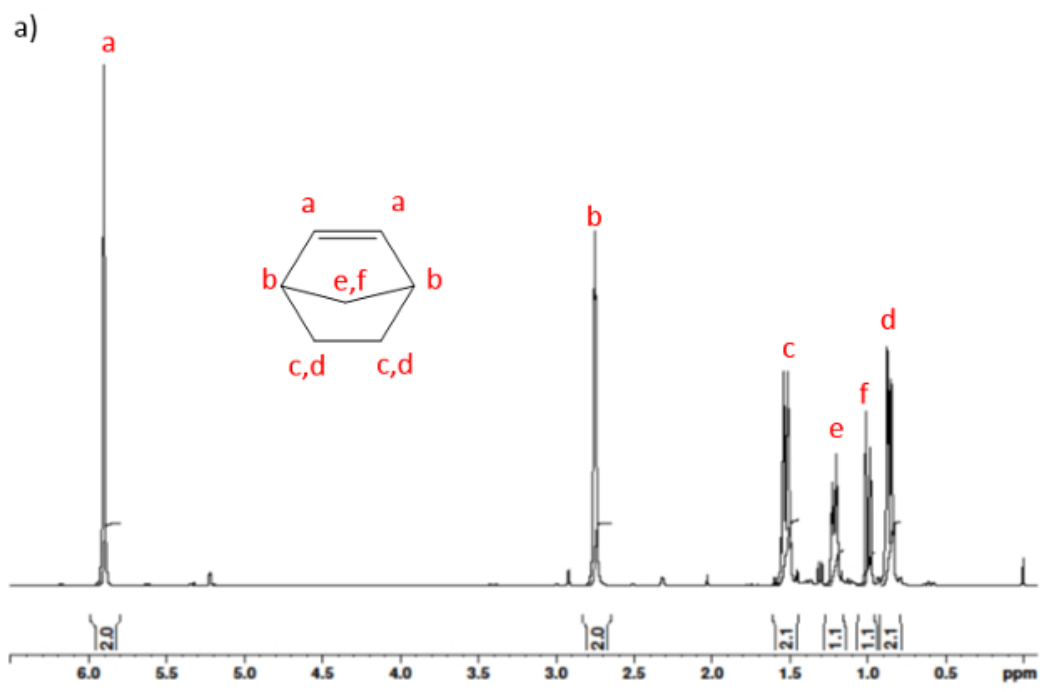

b)
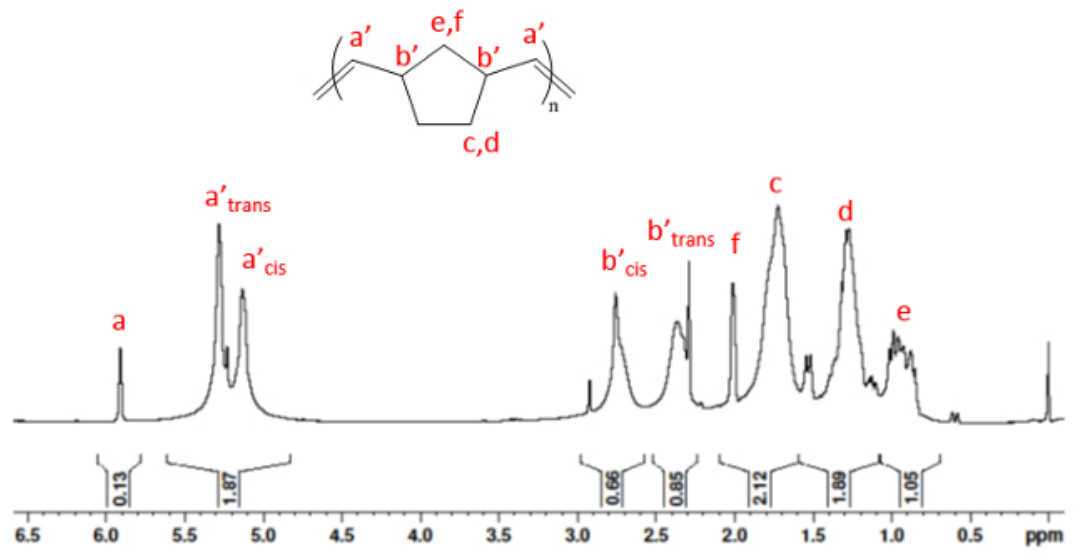

Figure 6: Photo ROMP in solution. ${ }^{1} \mathrm{H}$ NMR spectrum in $\mathrm{CD}_{2} \mathrm{Cl}_{2}(400 \mathrm{MHz})$ of the photopolymerization reaction medium (a) before irradiation and (b) after $10 \mathrm{~min}$ irradiation at $365 \mathrm{~nm}$. Please click here to view a larger version of this figure.

Copyright @ 2018 Journal of Visualized Experiments

November 2018 | 141 | e58539 | Page 9 of 12 


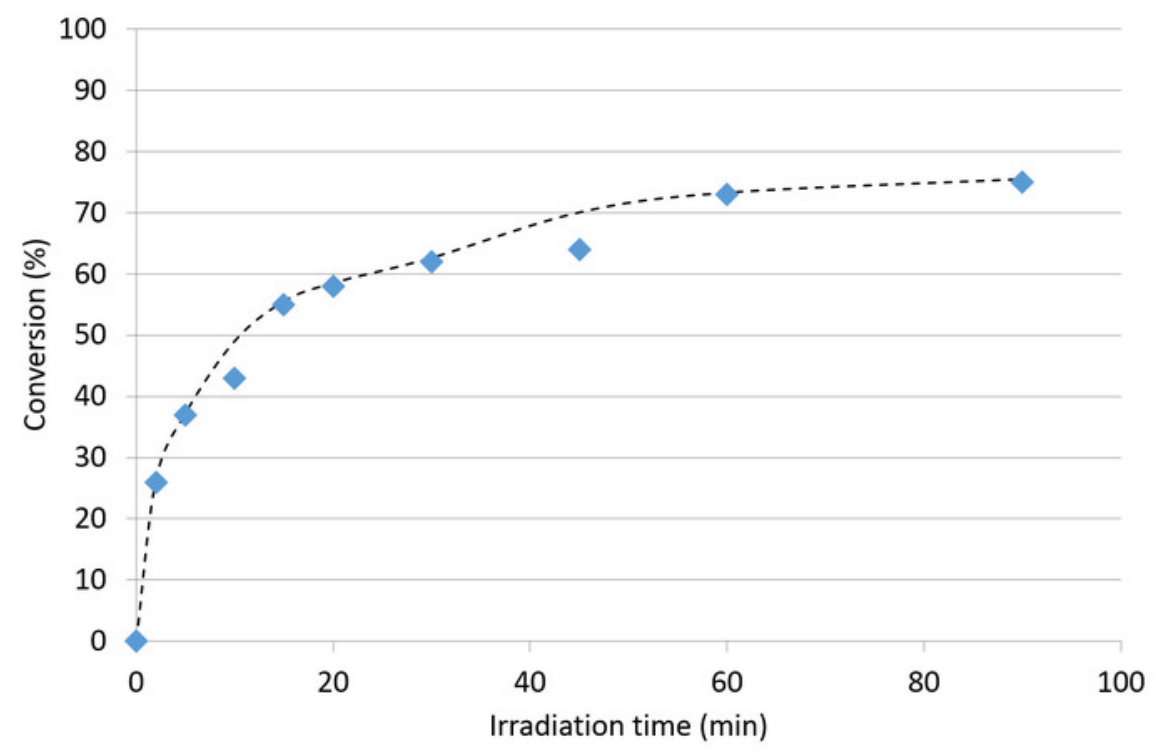

Figure 7: Evolution of photoROMP in miniemulsion with time. Nb conversion as a function of irradiation time in miniemulsion photoROMP. Please click here to view a larger version of this figure. 

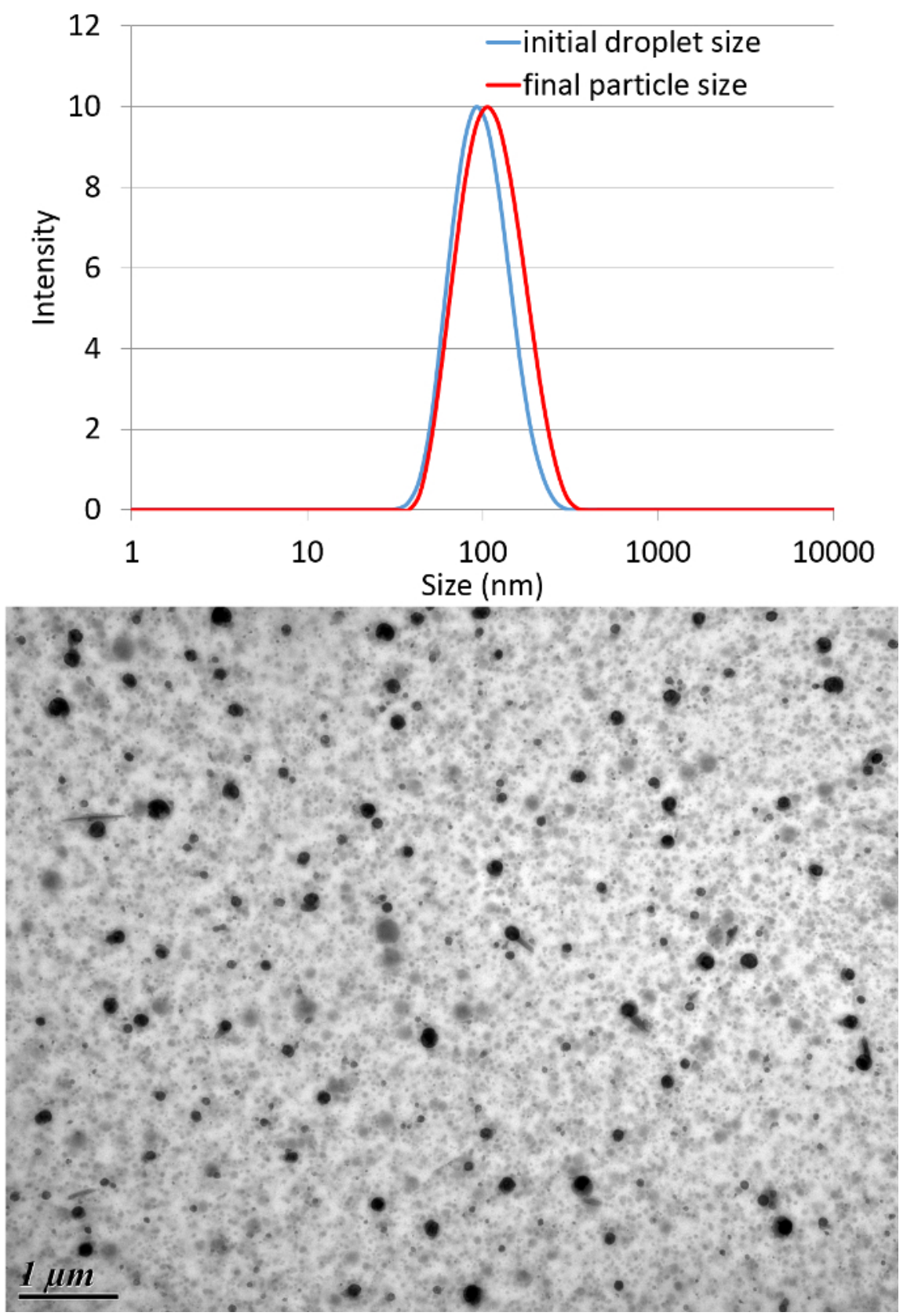

Figure 8: Characterization of polyNb particles. Shown are DLS data (top) of $\mathrm{Nb}$ miniemulsion and polyNb latex obtained after photopolymerization. TEM micrograph of final latex. Please click here to view a larger version of this figure.

\section{Discussion}

Reported here is an easy and versatile protocol for the in-situ generation of NHC upon UV-irradiation at $365 \mathrm{~nm}$. The anion exchange reaction between 1,3-dimesitylimidazolium chloride and sodium tetraphenylborate provides straightforward access to the NHC protected from $\mathrm{IMesH}^{+} \mathrm{BPh}_{4}{ }^{-}$in quantitative yield. Nevertheless, if using another starting imidazolium salt, the solvent employed to perform the metathesis reaction should be chosen with care so that it allows the solubilization of both starting salts (imidazolium salts and sodium tetraphenylborate) and the precipitation of the imidazolium tetraphenylborate product. As such, ethanol is often the most appropriate solvent to perform this reaction.

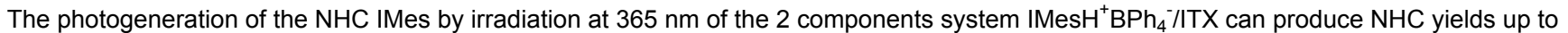
$50 \%$, but lower yields can be obtained depending on the experimental conditions employed. In particular, the use of solvents containing water or protic species favors secondary reactions such as the deprotonation of these protic species by $\mathrm{BPh}_{4}{ }^{-}$and/or the reprotonation of IMes, decreasing the overall yield of released IMes. Indeed, NHC are known to be sensitive to water and other impurity traces, so it is recommended to use dried solvents when attempting to photogenerate the NHC IMes. Despite their water/protic sensitivity, NHCs are much more reactive towards metallic substrates such as $\left[\mathrm{RuCl}_{2}(\mathrm{p} \text {-cymene })\right]_{2}$, which allows for the ROMP of $\mathrm{Nb}$ to be performed in miniemulsion. It has been noticed that the presence of dioxygen can also alter the course of the reaction. Indeed, dioxygen is known to react with ITX triplet, preventing the release of IMes. Because an electron transfer is involved during the generation of $\mathrm{NHC}$, the reaction is also assumed to be highly dependent on solvent 
polarity. Finally, when attempting to photogenerate IMes from ITX/IMesH ${ }^{+} \mathrm{BPH}_{4}{ }^{-}$in a reaction media, the latter should be chosen to provide good solubilization of the $\mathrm{IMesH}^{+} \mathrm{BPh}_{4}{ }^{-}$salt and no absorption of UV light up to $350 \mathrm{~nm}$.

As opposed to other methods that rely on temperature, dilution, or $\mathrm{pH}$ changes to generate in situ $\mathrm{NHC}$, this approach involves radiation as the external stimulus, with a distinctive advantage being spatial/temporal control of the reaction. Thanks to manifold polymerization reactions catalyzed/initiated by $\mathrm{NHC}$, we envision that a photolatent $\mathrm{NHC}$ can foster new photopolymerization reactions such as photoROMP as detailed in this study. In addition, because NHCs are well-established stabilizing ligands, we believe that the photochemical preparation of organometallic complexes may benefit from this photogenerating NHC system. Finally, because NHCs are employed as reactants or catalysts in many organic chemistry reactions, their photogeneration should be of interest to chemists who wish to involve NHCs in cascade reactions at specific times.

\section{Disclosures}

The authors have nothing to disclose.

\section{Acknowledgements}

Financial support by the French National Research Agency (ANR program: DS0304 2016, contract number: ANR-16-CE07-0016) and the

French Ministry of Research (doctoral grant of Emeline Placet) are gratefully acknowledged.

\section{References}

1. N-Heterocyclic carbenes: from laboratory curiosities to efficient synthetic tools. Royal Society of Chemistry. Cambridge. (2017).

2. Díez-González, S., Marion, N., Nolan, S.P. N-Heterocyclic Carbenes in Late Transition Metal Catalysis. Chemical Reviews. 109 (8), 3612-3676 (2009).

3. Fevre, M., Pinaud, J., Gnanou, Y., Vignolle, J., Taton, D. N-Heterocyclic carbenes (NHCs) as organocatalysts and structural components in metal-free polymer synthesis. Chemical Society Review. 42 (5), 2142-2172 (2013).

4. Naumann, S., Dove, A.P. N-Heterocyclic carbenes as organocatalysts for polymerizations: trends and frontiers. Polymer Chemistry. 6 (17), 3185-3200 (2015).

5. Naumann, S., Buchmeiser, M.R. Liberation of N-heterocyclic carbenes (NHCs) from thermally labile progenitors: protected NHCs as versatile tools in organo- and polymerization catalysis. Catalysis Science Technology. 4 (8), 2466-2479 (2014).

6. Naumann, S., Buchmeiser, M.R. Latent and Delayed Action Polymerization Systems. Macromolecular Rapid Communication. 35 (7), $682-701$ (2014).

7. Neilson, B.M., Bielawski, C.W. Photoswitchable NHC-promoted ring-opening polymerizations. Chemical Communication. 49 (48), $5453-5455$ (2013).

8. Teator, A.J., Tian, Y., Chen, M., Lee, J.K., Bielawski, C.W. An Isolable, Photoswitchable N-Heterocyclic Carbene: On-Demand Reversible Ammonia Activation. Angewandt Chemie International Edition. 54 (39), 11559-11563 (2015).

9. Pinaud, J., et al. In Situ Generated Ruthenium-Arene Catalyst for Photoactivated Ring-Opening Metathesis Polymerization through Photolatent N-Heterocyclic Carbene Ligand. Chemistry - A European Journal. 24 (2), 337-341 (2018).

10. Konishi, T., Sasaki, Y., Fujitsuka, M., Toba, Y., Moriyama, H., Ito, O. Persistent C60 anion-radical formation via photoinduced electron transfer from tetraphenylborate and triphenylbutylborate. Journal of the Chemical Society, Perkin Transactions. 2 (3), $551-556$ (1999).

11. Ogawa, K.A., Goetz, A.E., Boydston, A.J. Developments in Externally Regulated Ring-Opening Metathesis Polymerization. Synletter. 27 (2), 203-214 (2016).

12. Eivgia, O., Lemcoff, N.G. Turning the Light On: Recent Developments in Photoinduced Olefin Metathesis. Synthesis. 50 (1), $49-63$ (2018).

13. Monsaert, S., Vila, A.L., Drozdzak, R., Van Der Voort, P., Verpoort, F. Latent olefin metathesis catalysts. Chemical Society Review. 38 (12), 3360-3372 (2009).

14. Delaude, L., Demonceau, A., Noels, A.F. Synthesis and Application of New N-Heterocyclic Carbene Ruthenium Complexes in Catalysis: A Case Study. Current Organic Chemistry. 10 (2), 203-215 (2006).

15. Delaude, L., Demonceau, A. Retracing the evolution of monometallic ruthenium-arene catalysts for C-C bond formation. Dalton Transaction. 41 (31), 9257-9268 (2012).

16. Asua, J.M. Miniemulsion polymerization. Progress in Polymer Science. 27 (7), 1283-1346 (2002). 